\title{
The meanings of psychotherapy ${ }^{1}$
}

Daniel Hack Tuke first used the word 'psychotherapeutics' in 1872 (Ellenberger, 1970, p. 765). He defined the term psychotherapy in his dictionary (Tuke, 1892), published twenty years later, as 'treatment of disease by the influence of the mind on the body'. Advances in the field of the behavioural sciences and other events in the twentieth century have led to changes in the meanings of psychotherapy but there is still no consensus of opinion. Wolberg (1977), for instance, lists as many as thirty-six meanings and then adds his own, noting with some exasperation that 'few words in the lexicon of mental health field are as ambiguous as the term psychotherapy'. As a major activity or, to some, as the very raison d'être of psychiatry, psychotherapy seems to be easier to practise than to define. What do we mean when we say that we are engaged in psychotherapy with our patients?

A few general remarks about semantics may help to clarify the issue. Any living language is in a state of flux. Concepts change and words alter their meaning with the passage of time, so that there is a complex interaction between a historical epoch and the meaning of words. The vicissitudes in the definition of psychotherapy reflect, in one way or another, the history of behavioural science. No pretence is made of this being an essay on either the history of psychotherapy or semantics per se; at best, it is the history of a term.

In addition, it should be pointed out that if psychotherapy were to be defined simply as a 'talking cure', then its origins would necessarily have to be traced back to the period when man first used words for their healing power. Even in the distant past the value of words was acknowledged. Most societies, primitive and modern, share a belief in the power and sanctity of the word. Words could summon gods, destroy and, at times, heal. It is important here to note the distinction between 'primitive healing' and 'scientific therapy' (Ellenberger, 1970, p. 47). The etymology of psychotherapy (Greek psyche $=$ mind, and therapy $=$ treatment) clearly categorizes it as a treatment modality. The search for the origins of psychotherapy qua treatment to alleviate symptoms or cure disease is confined to the period when man aimed to identify putative psychological factor(s) in disease (Walker, 1959). Failure to take this distinction into account would be like searching for the origins of surgery at the time when man first used a sharp instrument on another human being.

The stated purpose of this editorial is, then, broadly speaking, semantic. There are, however, wider implications. The ambiguity of the term psychotherapy has led to mental health professionals finding themselves engaged in a variety of activities all under the general rubric of psychotherapeutics. Over and above the few 'orthodox' varieties, such as 'supportive psychotherapy' and 'psychoanalytical psychotherapy', a recent consumer's guide (Herink, 1980) lists as many as 250 forms of 'psychotherapy'. It is, furthermore, impossible to estimate the full range of activities that take place in the privacy of psychotherapeutic practice and to know whether there is anything common to these psychotherapeutic variants. Needless to say, this ambiguity is a source of bewilderment to consumers and research workers alike, and renders the profession vulnerable to criticism. A secondary aim of this editorial is to outline the historical roots of our present confusion regarding the meaning of psychotherapy. The next section adumbrates changes in the meaning of psychotherapy and is followed by a discussion of some implications of these changes.

Ancient Greek thought contained seminal ideas regarding the 'therapy of the word'; there are several references to the healing power of words in the Homeric epics and in the writings of various Greek philosophers. Indeed, ancient Greek culture is largely credited with having transformed scientific medicine from muta ars, art without words, into a discipline which uses words therapeutically. However, if one focuses on Greek medicine, rather than on the rest of ancient Greek literature, a

1 Address for correspondence: Dr C. V. Haldipur, Hutchings Psychiatric Center, Box 27, University Station, Syracuse, NY 13210, USA. 
different impression is obtained. Lain Entralgo (1970) notes that Hippocrates laid the foundation of scientific qua physiological medicine: the Hippocratic physician could have been and even began to be a psychotherapist but he did not do so adequately (p. 169). Simon (1980), similarly, concludes that "ancient medicine did not develop a concept of the healing power of words and dialogue just as it did not develop a concept of disturbances of the mind apart from disturbances of the body. On the contrary, one gets from the Hippocratic authors the sense that anything not couched in physiological and physical terms already touched on magic and charlatanism' (p. 227).

To challenge this tendency to trace the origins of much of Western science to ancient Greece, the shibboleth of Western scholarship, is tantamount to intellectual sacrilege. As Zilboorg (1941) points out, we are accustomed to think of our knowledge as deeply rooted and as having its source almost exclusively in Greek thought. 'As far as psychiatry is concerned', he writes, 'it is worthwhile to ponder over the possibility that Hindu thought, original and potent, travelled westward' (p. 31). Hindu medicine is largely credited with having recognized the importance of psychological factors in disease. Charaka-Samhita, a treatise on medicine estimated to have been written around the first century A.D., contains the following verses in a chapter on insanity (quoted in Haldipur, 1984):

The man who has become unhinged in his mind as the result of losing something that he dearly loves, should be consoled by the proffer of a substitute and words of comfort.

As regards the mental derangement resulting from an excess of desire, grief, delight, envy or greed, it should be allayed by bringing the influence of its opposite passion to bear on the prevailing one and neutralize(ing) it.

Although these two verses, and others in Hindu medical writings, suggest explicit recognition of psychological factors in diseases, especially insanity, Sanskrit, the ancient Indian language, does not have a word corresponding precisely to psychotherapy.

Mesmerism and hypnosis changed the existing paradigm and eventually led to Freud's development of psychoanalysis. There are several studies (e.g. Ellenberger, 1970; Chertok \& deSaussure, 1979) devoted to this subject. Relatively little, however, has been written about the contribution of Daniel Hack Tuke, the great-grandson of the founder of the York Retreat. His books were widely read in their day, and Freud's paper 'Obsessions and phobias' (1962, S.E. III, p. 74) contains a citation to his work. On Conolly's 'moral treatment', which was the dominant influence on psychiatry at the time, Tuke (Bucknill \& Tuke, 1858) wrote: 'To remove the cause of cerebral excitement is not moral treatment, and even to be kind and gentle in word and deed to the insane cannot rightly be called moral but physiologic treatment' (p. 486). For Tuke all interventions, moral or physiological, ultimately affected the body; to him insanity was no different from other physical diseases. However, he was aware of the role emotions played in disease: 'That a physical disease caused by moral emotion is susceptible to cure by an opposing emotion is undeniable in other regions of nosology than that devoted to the neuroses. Dyspepsia caused by anxiety is cured by prosperity and content' (p. 488).

Tuke devoted an entire book to the elucidation of various influences of the mind on the body; 'psychotherapeutics' were to be the practical application of this body of knowledge. He explained his choice of the term thus (Tuke 1872): 'phenomena involving restorative processes which justify the employment of (in addition to physical remedies) a reasonable psychopathy, or Psychotherapeutics - a preferable term in an age when the multiplication of pathies is undersirable' (p. 418).

Braid and Liébeault had by this time demonstrated the efficacy of hypnosis in relieving symptoms. The notion that the mind influenced the body was crucial for practice and for the idea of psychotherapy. Two of Tuke's contemporaries, Bernheim in France and van Eeden in Holland, used hypnosis and may share the credit for using the term psychotherapy. The mind was not the target of the enterprise but a conduit: psychological, i.e. non-physical, means were employed. This notion is reflected in Tuke's definition of psychotherapy as "the treatment of disease by the influence of the mind on the body'.

Liébeault, who founded the 'Nancy School', realized that it was not physical action which constitutes hypnosis but a psychological process, an idea, a verbal suggestion. His pupil, Bernheim, 
went a step farther in asserting that hypnosis was mere suggestion, thus giving predominant place to psychology and clearing the way for subsequent developments (Chertok \& deSaussure, 1979). Among many workers influenced by Liébeault and Bernheim were two Dutch physicians, van Eeden and van Renterghem.

Very little has been written about van Eeden outside his native Holland. With his colleague, van Renterghem, he operated a clinic in Amsterdam. In order to distinguish their work from that of other hypnotists who practised for the public, they changed the name of their activity to 'Suggestieve Psychotherapie' (Brinkgreve, 1981). The word suggestion was becoming increasingly vague in meaning, and was to be replaced by the fashionable new term, 'psychotherapy' (Ellenberger, 1970, p. 770). Van Eeden participated in a Congress on 'psychotherapy' held in London in 1894, by which time the term 'psychotherapy' had gained widespread acceptance.

In the introduction to their book, Psycho-thérapie, van Renterghem \& van Eeden (1894) comment as follows:

que la psycho-thérapie, non comprise comme 'hypnotisme' simplement, mais comme l'art de guérir par voies psychiques, donne déjà des résultats satisfaisants nonobstant la courte durée de son existence comme branche de la médecine exercée méthodiquement (p. 1) (psychotherapy, understood not simply as hypnotism, but the art of curing by psychological means, has in spite of its short existence as a systematic branch of medicine, given satisfactory results).

To place van Eeden in chronological perspective with Freud, whose first major psychoanalytical works were published between 1893 and 1895, it may be noted that Freud is said to have inscribed a gift to him: 'Frederick van Eeden, physician and poet, who suspects so many of the hidden secrets of the mind [soul]' (quoted in Brinkgreve, 1981). Jones (1955, II, p. 368) wrote 'van Eeden, a Dutch psychopathologist, is now remembered more as a poet, essayist and social reformer; both Freud and I have been unsuccessful in getting him to accept psychoanalytic theories'.

In his paper on psychotherapy, Freud (1962) explicitly acknowledged his debt to the Nancy School, particularly the work of Liébeault and Bernheim (S.E. VII, p. 258). His stay in Paris at the Salpêtrière was also crucial to the subsequent development of psychoanalysis (Chertok, 1970). The concepts and metaphors of hypnotists like Charcot were gradually transformed into psychoanalytical metapsychology (Chertok, 1968) and eventually led to key concepts of mental events and mental disorders. Pierre Janet (1924), a pupil of Charcot at the Salpêtrière, characterizes the transformation to Freudian metapsychology thus:

[Freud] changed first of all the terms I was using: what I had called psychological analysis he called psychoanalysis; what I had called psychological system in order to designate that totality of facts of consciousness and movement, whether of members or of viscera, whose associations constitute the traumatic memory, he called the complex; he considered a repression what I considered a restriction of consciousness; what I referred to as a psychological dissocation, or as a moral fumigation, he baptized with the name of catharsis (p. 41).

Breuer's patient, Anna O., is credited with first using the term 'talking cure'. The abandonment of hypnosis and the recourse to free association were major milestones in the history of psychotherapy. 'Words are the essential tool of mental treatment', according to Freud (1962, S.E. VII, p. 283). By this time he had also begun to develop the concept of 'mental events', and his 1905 definition of psychotherapy incorporates this important notion of the 'pathological phenomenon of mental life'. His definition is comprehensive and evocative of many subsequent developments.

'Psyche' is the Greek word which may be translated 'mind'. Thus, psychical treatment means 'mental treatment'. The term might accordingly be supposed to signify 'treatment of the pathological phenomenon of mental life'. This, however, is not its meaning. 'Psychical treatment' denotes rather, treatment taking its start in the mind, treatment (whether of mental or physical disorders) by means which operate in the first instance and immediately upon the mind (italics in original) (S.E. vII, p. 283).

In the original German Freud used the word Seele, which may be translated as 'soul' rather than 'mind'. 
There are two concepts embedded in this definition that were to influence future concepts of psychotherapy. First is the mention of the pathological phenomenon of mental life. Repressed memories, complex and psychic trauma were introduced as analogous to the lesions that cause physical diseases. The purpose of psychotherapy was to aim at this putative 'pathological phenomenon', without whose removal cure could not take place. Already at the Salpêtrière it had become clear that psychical trauma, and not physical injury alone, could give rise to symptoms. Second is the notion of 'mental' disorder itself. For Freud, psychotherapy was useful for physical as well as mental disorders. The idea of mental disorder, apart from physical disorder, was a logical corollary to the concept of pathological mental phenomenon and a departure from the contribution of Tuke, that psychotherapy ultimately affected the body and that psychiatric disorders were essentially no different from physical diseases.

Post-Freudian vicissitudes in the meaning of psychotherapy in some ways relate to the notions of 'pathological phenomemon of mental life' and 'mental disorder'. Both are subjects of debate and have led to subsequent changes in the meaning. It is not uncommon for psychotherapists to speak of the resolution of the repressed conflict as a goal in therapy. In so doing, they reify the 'complex' and render it analogous to a lesion in physical disease. For example, Hinsie \& Shatzky (1953) describe psychotherapy as an enterprise designed to eliminate 'abnormal constituents of the mind'. Clearly, this notion raises several legitimate epistemic issues, and most contemporary definitions avoid reference to mental events or to 'abnormal constituents of the mind'.

Freud's reference to mental diseases in his definition of psychotherapy introduced a new dimension. Viewed separately from physical diseases, mental diseases were seen as manifested by psychological symptoms and caused by 'pathological mental events'. Psychotherapy was to be a specific treatment, owing its effectiveness to its ability to deal with putative pathological mental events. The concept has proved to be a Pandora's box, adopted by some lexicographers and discarded by others. Both the Webster's Collegiate Dictionary and the Oxford English Dictionary allude to either 'disease' or its innocuous counterpart 'disorder'. In contrast, a perusal of two recent editions of psychiatric glossaries issued by the American Psychiatric Association reveals that the reference to 'disease' has been all but abandoned. The fourth edition (APA, 1975) had a separate entry under the rubric 'medical psychotherapy', and psychotherapy was referred to as 'a generic term for the treatment of mental and emotional disorders'. In 1980, however, the term is defined as: 'A process in which a person who wishes to relieve symptoms or resolve problems in living or is seeking personal growth enters into an implicit or explicit contract to interact in a prescribed way with a psychotherapist' (italics in original). This may well be a uniquely North American phenomenon. A British glossary (Leigh et al. 1977) defines psychotherapy as a 'method of treating illness based on the use of psychological rather than physical techniques' (p. 305, my italics).

Reduced to its quintessential minimum, psychotherapy consists of communications (usually verbal) between two or more persons. How is this communication different from others in our everyday lives - say that between friends, or a publican and his customer? Orne (1975) has clarified the point eloquently: 'In contrast to all other medical-treatment procedures that are defined by what is done to the patient, psychotherapy is defined more by who does it - by the role relationship and the training of the therapist...It is not specifics of the interactions but the context, the purpose, and the special infrastructure that in fact define it as psychotherapy' (p. 5, italics in original). The contractual aspects and reference to the training of psychotherapists are incorporated in most contemporary definitions (e.g. Campbell, 1981).

The historical study of psychiatry is inseparable from an appreciation of its current problems (Hunter \& Macalpine, 1963). Over one hundred years after the introduction of the word 'psychotherapy' vicissitudes in its meaning must be viewed in a historical context. Key concepts were developed in the behavioural sciences which, in turn, brought about changes in the meaning. First, there was the discovery of the efficacy of hypnosis. Physical symptoms, which today would be called 'conversion symptoms' or hysteria, were relieved by non-physical verbal means. Hypnotists had already begun to realize that psychological trauma, and not physical injury alone, would give rise to symptoms. The concept of 'mental events' was later elaborated by Freud around the turn 
of the century. A logical corollary was the separation of 'mental illness' from physical illnesses. Neurosis, a term coined several decades earlier by the Scottish physician Cullen, took on a new meaning in the light of Freud's work, and soon became the paradigmatic state for which psychotherapy was to be the specific treatment. In the past few decades it has become necessary to specify the contract, implicit or explicit, between the psychotherapist and the patient. With the widening scope of psychotherapy and its employment by various mental health professionals, the issue of relevant training is being examined.

The concept of psychotherapy has evolved in stages. In succession, questions concerning what?, for whom?, how?, and finally who? of psychotherapy have been raised, so far with only partial answers. It may be possible to draw an analogy, however tenuous, with some treatments in physical medicine, where elucidation of the mechanisms of action and the indications for therapy follow the (often) serendipitous discovery of drugs. There is, however, one important difference with psychotherapy, namely the need to specify who provides the treatment.

In defining psychotherapy, lexicographers and various authors appear to emphasize selectively one or another dimension, either singly or in combination. This tendency to stress the method (words), the condition for which it is used (mental disorders) or its alleged mechanism of action (removal of abnormal constituents) reflects various stages in the evolution of the concept and contributes to our present confusion. A truly comprehensive definition, if at all possible, will have to incorporate all the characteristics of psychotherapy.

The problem of definitions is by no means unique to psychiatry. Several decades ago Crookshank (1953) warned the medical profession about its inability to define terms, and his words may well serve as an epigraph for every medical and psychiatric glossary.

Medicine is today an Art or Calling, to whose exercise certain sciences are no doubt ancillary; but she has forfeited pretension to be deemed a Science, because her Professors and Doctors decline to define fundamentals or to state first principles, and refuse to consider, in express terms, the relations between things, thoughts and words involved in their communications to others (p. 338).

If psychotherapy were indeed an object, say a chemical like aspirin, it could have been subjected to objective analysis by a biochemist. As a procedure, one can either scrutinize what psychotherapists actually do or listen to what they say they do. In either case, the situation is bewildering. For example, a perusal of different varieties of psychotherapy (Herink, 1980) leads inevitably to the conclusion that the psychotherapist and the patient do not necessarily talk; they may scream (scream therapy), or just breathe (breathing therapy), and it is an open question what goes on in ' $\mathrm{C} 1 \mathrm{C} 2$ project therapy' or 'cooking as therapy'. Even if one were to concede that these activities may be useful for some patients, are they truly varieties of psychotherapy? A major source of this confusion, and our present semantic imbroglio, is the way in which the term is defined. If psychotherapy were to be defined simply as the treatment of mental and emotional problems, then Christian Science, psychosurgery and convulsive therapy will have to be included as psychotherapeutic treatment. Mutatis mutandis, each definition determines what comes to be called psychotherapy.

One way to appreciate the change in the meaning over the past one hundred years is to juxtapose Tuke's 1892 definition with that in the recent glossary of the American Psychiatric Association. It is clear that the most profound change has been the deletion of reference to disease. This widening scope of psychotherapy began during Freud's lifetime, as Jones acknowledged: 'The wider recognition of the nature of neurosis has meant that a great many conditions and traits of behavior are as a result seen in a quite different light. Minor eccentricities which were formerly labeled as quirks or whimsies are appreciated as being of neurotic origins, whether they call for treatment or not' (Jones, 1955, III, p. 434).

Jones' comments have to be contrasted with Freud's (1962) assertion that 'what analysis achieves for neurotics is nothing other than what normal people bring about for themselves without its help' (S.E. XXIII, p. 225). Through psychotherapy normal persons, by the current American Psychiatric Association definition, can hope to achieve what has been nebulously termed 'personal growth'. The net result has been that psychotherapy has acquired a place in all aspects of human life - from 
birth to death, factories to hospitals, and schools to the political arena. We now live in what has been pejoratively called the 'psychological society' (Gross, 1978). Even the dead are subjected to psychological post-mortems. Increasingly psychotherapeutic activities have become responses to a widespread demand for reassurance, hope and support, 'to a part of the human condition' (Shepherd, 1984). As the indications for psychotherapy have increased, so have the ranks of psychotherapists. America, which resisted for so long Freud's call for lay analysts, now has tens of thousands of psychologists, social workers and nurses offering psychotherapy. Whatever the merits of this 'demedicalization' of psychotherapy may be, an interesting semantic issue has arisen. If we are not treating true diseases or illnesses, can we really refer to what we do as psychotherapy? Alas, the alternative term proposed by Szasz (1978), iatrology, also has medical connotations (Greek iatros $=$ physician).

In conclusion, one would have to agree with a recent editorial in the Lancet (1984) that 'psychotherapy will doubtless survive but will drift even more into the fringes of medicine, an option only for those who are prepared to pay and ask no questions about outcome'. Calling the enterprise an art (Storr, 1980) does not obviate the need to define the term properly. It remains 'a nebulous term with widely differing connotations' (Bloch, 1982). We seem to be saying, like Lewis Carroll's Humpty Dumpty, 'When I use a word, it means just what I choose it to mean - neither more nor less'. The trouble is that too many of us are saying it.

C. V. HALDIPUR

\section{REFERENCES}

American Psychiatric Association (1975, 1980). A Psychiatric Glossary. American Psychiatric Association: Washington, D.C.

Bloch, S. (1982). What is Psychotherapy? p. 1. Oxford University Press: Oxford.

Brinkgreve, C. (1981). Op zoek naar verlossing - Frederik van Eeden en de psychotherapie, Maatstaf 29 (5), 22-31.

Bucknill, J. C. \& Tuke, D. H. (1858). Manual of Psychological Medicine. Hafner: New York (reprinted, 1968).

Campbell, R. J. (1981). Psychiatric Dictionary. Oxford University Press: New York.

Chertok, L. (1968). From suggestion to metapsychology. British Journal of Medical Psychology 41, 95-115.

Chertok, L. (1970). Freud in Paris: a crucial stage. International Journal of Psychoanalysis 51, 511-520.

Chertok, L. \& deSaussure, R. (1979). The Therapeutic Revolution: from Mesmer to Freud. Brunner/Mazel: New York.

Crookshank, P. G. (1953). The importance of a theory of signs and a critique of language in the study of medicine. In The Meaning of Meaning (ed. C. K. Ogden and I. A. Richards), p. 338. Harcourt, Brace \& Co: New York.

Ellenberger, H. (1970). The Discovery of the Unconscious. Basic Books: New York.

Freud, S. (1962). The Standard Edition of the Complete Works (transl. J. Strachey). Hogarth Press: London.

Gross, M. L. (1978). The Psychological Society. Random House: New York.

Haldipur, C. V. (1984). Madness in ancient India. Comprehensive Psychiatry 25, 344-355.

Herink, R. (1980). The Psychotherapy Handbook. New American Library: New York.

Hinsie, L. E. \& Shatzky, J. (1953). Psychiatric Dictionary. Oxford University Press: New York.
Hunter, R. \& Macalpine, I. (1963). Three Hundred Years of Psychiatry 1535-1860, p. ix. Oxford University Press: New York.

Janet, P. (1924). Principles of Psychotherapy. MacMillan: New York.

Jones, E. (1955). The Life and Works of Sigmund Freud. Basic Books: New York.

Lain Entralgo, P. (1970). The Therapy of the Word in Classical Antiquity. Yale University Press: New Haven.

Lancet (1984). Editorial: Psychotherapy: effective treatment or expensive placebo? i, 83-84.

Leigh, D., Pare, C. M. B. \& Marks, J. (1977). A Concise Encyclopaedia of Psychiatry. University Park Press: Baltimore.

Orne, M. T. (1975). Psychotherapy in contemporary America: its development and context. In American Handbook of Psychiatry, Vol. 5 (ed. S. Arieti), p. 5. Basic Books: New York.

Shepherd, M. (1984). What price psychotherapy? British Medical Journal 288, 809-810.

Simon, B. (1980). Mind and Madness in Ancient Greece: the Classical Roots of Modern Psychiatry. Cornell University Press: Ithaca.

Storr, A. (1980). The Art of Psychotherapy. Metheun: New York.

Szasz, T. (1978). The Myth of Psychotherapy. Anchor/ Doubleday: Garden City.

Tuke, D. H. (1872). Illustrations of the Influence of the Mind upon the Body in Health and Disease. J.\&A. Churchill: London.

Tuke, D. H. (1892). Dictionary of Psychological Medicine, Vol. 2. Ayer: New York (reprinted 1976).

van Renterghem, A. W. \& van Eeden, F. (1894). Psycho-thérapie. Société d'éditions scientifiques: Paris.

Walker, N. (1959). A Short History of Psychotherapy. Noonday Press: New York.

Wolberg, L. R. (1977). The Technique of Psychotherapy. Grune \& Stratton: New York.

Zilboorg, G. (1941). A History of Medical Psychology. Norton: New York. 